\title{
Multidisciplinary Design and Optimization of the Silent Aircraft
}

\author{
A. Diedrich, J. Hileman, D. Tan, K. Willcox, Z. Spakovszky \\ Department of Aeronautics and Astronautics \\ Massachusetts Institute of Technology
}

\begin{abstract}
A "silent ${ }^{\dagger}$ aircraft" is defined to be an aircraft that, in a typical urban area, is inaudible outside of the airport boundary. This paper describes the creation, implementation, and use of an integrated design tool to predict and optimize the performance and costs associated with producing a novel, commercial aircraft design with a step change in noise reduction. The silent aircraft uses a highly integrated configuration where a quiet propulsion system is embedded in a Blended-Wing-Body type airframe. This allows the shielding of forward radiated engine noise and the extensive use of acoustic liners. Multidisciplinary aircraft design models, which use a combination of simple physics and empirical relations, are adapted for the silent aircraft configuration. These models are used in conjunction with a multidisciplinary planform optimization capability. The resulting silent aircraft design is assessed in terms of performance and acoustic signature. Significant component noise reductions can be achieved with a design that has a fuel burn competitive with next-generation commercial aircraft. Barriers to achieving the aggressive noise goal of the Silent Aircraft Initiative and the associated required technology developments are described.
\end{abstract}

\section{Introduction}

Designing for noise is a highly integrated problem that must take into account engine and airframe design, aircraft operation, airline economics, and noise generation. This research targets the design of a novel aircraft with a radical reduction in noise - an aircraft that, in a typical urban area, is inaudible outside of the airport boundary. The aircraft design and assessment framework described in this paper places noise as the primary design goal, by bringing together multidisciplinary design tools, noise assessment tools, and innovative concepts such as a more closely integrated airframe and propulsion system.

Multidisciplinary design optimization (MDO) provides a formal framework which simultaneously considers the effects of different disciplines and their interactions. Exploration of the design space via optimization algorithms allows high-level design decisions and the quantitative assessment of trade-offs. Studies using MDO to aid in conceptual aircraft design have been made in numerous areas with considerable success. ${ }^{1-4}$ Venter and Sobieszczanski-Sobieski showed that traditional metrics like aircraft range can be extended through variations that might otherwise seem only loosely coupled. ${ }^{5}$ In their study of transport wing optimization, optimal range was achieved not only through overall wing shape changes, as would be expected, but also by a choice of construction technique whereby the internal spar was removed while the use of skin

\footnotetext{
*Corresponding author. 77 Massachusetts Ave. 37-447, Cambridge, MA 02139. Email: kwillcox@mit.edu

$\dagger$ "Silent" in this context does not refer to absence of acoustic sources.
}

stiffeners was incorporated. This exploitation of the interplay between disciplines (here, aerodynamics and structures) is typical of MDO in conceptual design.

Another objective that is often minimized in aircraft MDO is maximum takeoff weight (MTOW). By minimizing MTOW, designers hope to produce an inherently inexpensive aircraft by producing a small aircraft, while incorporating the fuel weight into the objective as part of the MTOW, so that both the acquisition costs and the operational costs are low. This technique produces particularly impressive results when the coupling of the disciplines in an airframe are strong, as in Boeing's Blended-Wing-Body (BWB) concept. ${ }^{6,7}$ Wakayama demonstrated that MDO codes can be used to both balance and reduce the MTOW of an aircraft simultaneously by exploiting geometric changes to the airframe. ${ }^{4}$

More recently, environmental considerations have been included in MDO-based design approaches. Antoine et al. applied multidisciplinary optimization to determine the extent to which noise can be traded against other performance measures. ${ }^{8-10}$ This work showed that, of the different figures of merit that were optimized (takeoff weight, operating cost, noise, nitrous oxide emissions, and fuel burn), optimization for noise required the greatest concessions in the other potential objectives. For conventional tube-and-wing aircraft with 2020 technology levels, in order to achieve a cumulative 15 EPNdB decrease in total certification noise, operating costs rose $26 \%$, MTOW rose $27 \%$, fuel load rose $17 \%$, and $\mathrm{NO}_{x}$ emissions rose $33 \%$ relative to the aircraft designed for minimum operating costs.

The extremely high cost to reduce noise is indica- 
tive of how poorly suited current jet aircraft are to modification for radical reductions in noise. The question arises what an aircraft would look like that had noise as a design goal with minimal penalties in performance and emissions. The idea of this paper is to combine a multidisciplinary planform optimization tool with first-principles and empirically-based design and acoustic prediction methods to explore unconventional, innovative airframe configurations for a step change in noise reduction and competitive performance.

At the advent of jet aviation, transports made simultaneous steps towards lower fuel burn and lower noise by switching to turbofans, and then to high bypass-ratio turbofans. However, the decline in noise generated by aircraft has always been partially countered by the increased use of air travel. Now that reductions in noise per takeoff or landing have slowed, FAA estimates predict that the two factors, increased operations and decreased noise per operation, will completely offset each other, so that no net progress will be made in reducing societal exposure to aviation noise (Figure 2 in Waitz et al. ${ }^{11}$ ). The incremental gains made by improving the acoustic performance of turbofans and modifying procedures to mitigate noise have pushed current aircraft configurations close to the limits of low noise potential.

Innovative aircraft concepts were explored through an assessment of the feasibility of a functionally silent aircraft by Pilczer ${ }^{12}$ and Manneville et al. ${ }^{13}$ This work showed that many challenges exist, but that a combination of noise reduction technologies integrated on a revolutionary airframe could potentially achieve drastic noise reductions, on the order of $22.5 \mathrm{~dB}$ on takeoff and $30 \mathrm{~dB}$ on approach. These reductions would be achieved through extreme changes to airframe, engines, flight paths, procedures, and controls. They would also require the clearing of very large technological and regulatory hurdles.

Alternative approaches to achieving dramatic reductions in noise are proposed by Lilley, ${ }^{14}$ using a combination of significant increases in low speed aircraft performance and exploitation of the inverse-square law that governs sound propagation. If the maximum lift capability of aircraft can be substantially increased through circulation control without increasing noise, then aircraft can decrease their takeoff and touchdown speeds, increase departure and approach angles, and take off and land in shorter distances. As a result, aircraft could land and take off near the mid-point of current runways, thereby maintaining a greater altitude outside the airport boundary. Lilley also advocates changing land use patterns directly adjacent to airports so that less noise-sensitive industrial-type operations can take over the area which is often currently occupied by residences. This land-use change in combination with the performance changes detailed above have the potential to reduce the noise reaching residential areas by $20 \mathrm{dBA} .{ }^{14}$

\section{Scope of the Paper}

The work presented in this paper is unique and different in that multidisciplinary planform optimization is applied to an unconventional airframe configuration with a closely integrated propulsion system to yield a step change in noise reduction at potentially minimal or no penalty in performance. This is explored through employment of innovative low-noise technologies and revolutionary changes in aircraft configuration combined with a rigorous assessment of design trade-offs. The goals of this research are (1) to establish a multidisciplinary design framework with noise as a primary objective, (2) to explore the design space and rigorously assess the proposed aircraft configuration in terms of aerodynamic performance and acoustic signature, and (3) to delineate technological barriers to achieving the step change in noise reduction at performance levels competitive with next generation aircraft.

In the following section, the configuration of the proposed silent aircraft is detailed, followed by a description of the multidisciplinary design and noise assessment tools. A performance and acoustic assessment of the silent aircraft design is then presented. Using this assessment, conclusions are drawn that provide guidance in addressing the key barriers to achieving the goal of a "silent aircraft".

\section{The Silent Aircraft Configuration}

In the context of this work a "silent aircraft" is defined to be an aircraft that, outside of the airport perimeter, is inaudible in a typical, noisy urban area. While noise is the primary design goal, the technology and design decisions to achieve this ambitious noise decrease are constrained to those that result in operating costs within the range of competition with next-generation commercial aircraft, such as the 787 .

The Silent Aircraft eXperimental (SAX) configuration is based upon a Blended-Wing-Body (BWB) aircraft. The BWB is a revolutionary aircraft concept that integrates the lifting surface, passenger cabin, engine inlets, and control surfaces to achieve large reductions in takeoff weight, fuel burn, and installed thrust. ${ }^{7}$ The SAX configuration builds upon the aerodynamic and operational benefits of the BWB, and incorporates design changes needed to achieve radical levels of noise reduction, assuming technology levels consistent with a 2030 entry into service date.

Several factors come together to position the SAX as an attractive configuration for a low-noise aircraft. One of the key characteristics is aerodynamic efficiency of the airframe. An airframe without a separate tail and with smooth lifting surfaces and minimally exposed edges and cavities will be an inherently low-noise design. In addition, the integration of the fuselage, 
wing, and control surfaces provides an airframe that achieves increased aerodynamic and structural efficiency. These characteristics will help to offset the potentially higher operating costs associated with the silent engine design. The SAX configuration also presents an excellent opportunity for shielding of engine noise.

The large wing area inherent in the SAX configuration will help to keep thrust loading (the weight of the aircraft divided by the installed thrust) reasonable, as Table 1 illustrates. Attempts at low-noise optimization of conventional configurations in the past have yielded thrust loadings that were relatively low (meaning a relatively large engine thrust per unit of aircraft weight), on the order of $2.37 \mathrm{lb} / \mathrm{lbf} .^{10}$ This is the result of using ultra-high bypass ratio (UHBR) engines, which keep takeoff noise low by using low-speed exhaust velocities, but suffer from very large thrust lapse at altitude. Thrust lapse is the reduction in thrust from sea level to cruise as flight Mach number is increased.

Table 1 Maximum thrust loadings of various commercial aircraft and a BWB design. ${ }^{7,15}$

\begin{tabular}{|c|c|}
\hline Aircraft & Thrust loading $(l b / l b f)$ \\
\hline $737-700$ & 3.40 \\
$747-400$ & 3.52 \\
$777-300 \mathrm{ER}$ & 3.32 \\
A340-500 & 3.68 \\
800 pax $B W B^{7}$ & 4.45 \\
\hline
\end{tabular}

The SAX also has an inherently high internal volume due to the long, thick center section of the airframe. This lends itself well to further integration of the engine and airframe. Concepts such as boundary layer ingestion (BLI) are currently being explored and yield reductions in required thrust with benefits in fuel burn. This yields challenges in the design of low-loss inlet ducts, the control of inlet flow distortion, and the integration of the turbomachinery. The SAX's center body is thick enough to allow moderately-sized high bypass ratio turbofans to be partially embedded into the trailing edge. The propulsion system of the SAX configurations discussed in this paper consists of four UHBR engines integrated in the airframe. A distributed propulsion system is currently being investigated for future designs.

\section{Multidisciplinary Design Optimization Framework}

In order to explore the conceptual design space for unconventional airframe configurations and innovative low-noise technologies, a design framework with a low turn-around time needs to be established. As depicted in Figure 1, this multidisciplinary design optimization framework consists of a suite of noise prediction methods, a modified version of WingMOD, ${ }^{4}$ a Boeing proprietary MDO tool used extensively in the design of the BWB, and a set of first-principles and empiricallybased aircraft design modules that address design issues for the disciplines of propulsion, aerodynamics, structures and weight, while considering mission elements of takeoff, climb, and cruise.

Initial estimates of aircraft weight and performance are provided by WingMOD to specify an initial design, complete with thrust levels, weight, and estimated fuel load. WingMOD is also used to conduct optimization of the planform, which is then used as an input to the aircraft design modules. As described in more detail below, the WingMOD optimization strategy is selected to be minimization of MTOW, since an aircraft with a given level of technology becomes quieter as the weight is reduced. The aircraft resulting from the initial sizing process is evaluated over the specified design mission to determine if it has the required thrust at each mission point and the required fuel to complete the mission. The process then iterates as shown in the loop on the right of Figure 1, considering both design and reserve missions, until the design achieves both thrust and fuel requirements. A design that meets the mission and performance requirements is then assessed for noise using empirical noise source prediction models and a propagation model that accounts for airframe shielding. Iteration between the acoustic models and the aircraft design modules is used to explore the design space and complete the conceptual design. Following this, a detailed three-dimensional aerodynamic analysis is conducted beyond those elements shown in Figure 1. This is not within the scope of this paper; a detailed discussion of this topic can be found in Hileman et al. ${ }^{16}$ In the following discussion, each of the main elements in the SAX design framework is outlined.

\section{WingMOD}

As described by Wakayama, ${ }^{4}$ WingMOD is an MDO code that incorporates performance, aerodynamics, loads, weights, balance, stability, and control considerations. WingMOD uses low-fidelity analyses to quickly analyze an aircraft over five mission configurations and 26 flight conditions.

For this research, WingMOD is used in concert with the first-principles based aircraft design tools as a planform source, a weight model basis, and as the embodiment of expertise gained by others who have been researching blended-wing-body configurations over the past decade. The SAX design in particular requires control of certain constraints and variables within WingMOD in order to accurately model the changes made in moving from a BWB to the SAX configuration with an embedded propulsion system. Table 2 lists the particular constraints and variables modified in order to produce the SAX designs.

WingMOD models the aircraft as a series of span- 


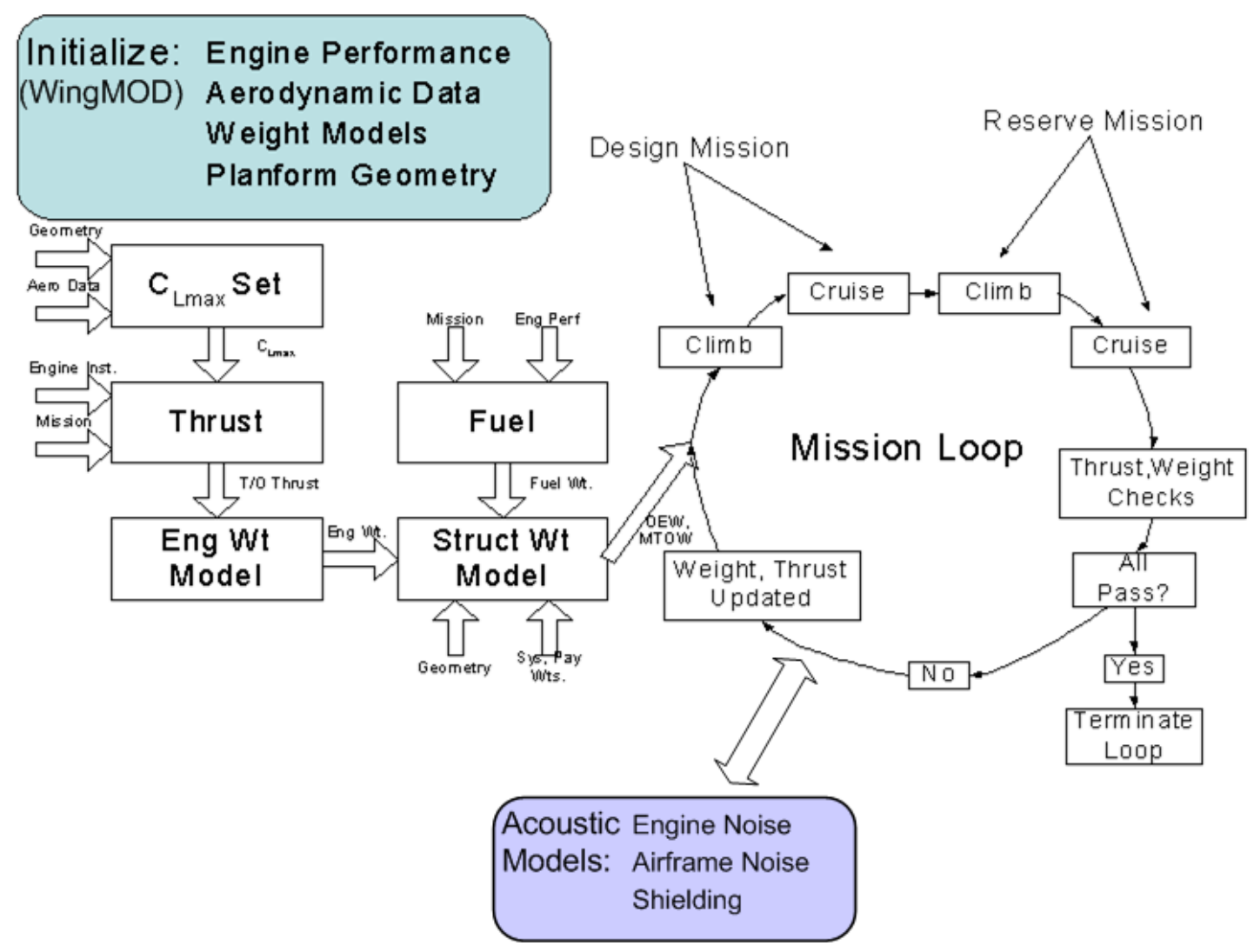

Fig. 1 The SAX design framework comprises three major components: (1) a set of first-principles and empirically-based modules for aerodynamics, propulsion, weights, and mission, (2) a suite of noise prediction methods, and (3) a version of WingMOD modified for the SAX configuration.

wise elements. A modified vortex-lattice code and monocoque beam analysis are coupled to generate static aeroelastic loads. The aircraft is trimmed at a variety of flight conditions. Loading and induced drag are calculated from the resultant loading data, and are then combined with profile and compressibility drag from empirical models. Structural weight is set by considering the maximum elastic loads over all of the flight conditions, and sizing the structure based upon bending strength and buckling stability. Maximum lift is determined using a critical section method, wherein it is assumed that the planform is at maximum lift when any individual spanwise element is at its maximum coefficient of lift. ${ }^{4}$

\section{Acoustic Models}

The noise prediction is based upon a set of semiempirical models that predict both the source strength and the modification to the acoustic waves as they propagate from the source. The result of the predictions is a footprint of ground noise for a given aircraft configuration and location.

The engine noise model consists of four modules: the Heidmann Fan Noise Module, ${ }^{17}$ the Stone Jet Noise Module, ${ }^{18}$ the General Electric (GE) Turbine Noise Module, ${ }^{19}$ and the Matta Combustion Noise Module. ${ }^{20}$
Additional information on the engine design, the procedure for determining its noise emission, as well as recent advances on its mitigation can be found in works by Hall and Crichton. ${ }^{21-23}$

The airframe shielding of forward radiating engine noise was approximated using a boundary element model of a single monopole placed above the SAX airframe as described in Agarwal and Dowling. ${ }^{24}$ The mitigation of engine noise by the acoustic lining of the inlet and exit ducts was estimated using information provided by Rolls Royce that was thought to yield a conservative estimate of the noise reduction. ${ }^{25}$ Work is ongoing to improve upon these estimates.

The airframe noise was computed as the sum of the airfoil self-noise, leading edge slat noise, elevator noise, and undercarriage noise. Airfoil self-noise, which is created by the boundary layer scattering at the trailing edge, was estimated using a procedure that combines aeroacoustic aspects of Ffowcs-Williams and Hall, ${ }^{26}$ Brooks et al. ${ }^{27}$ and Lockard and Lilley ${ }^{28}$ with boundary layer properties estimated from a viscous airfoil design tool. Slat noise was estimated based upon the average wing chord and wing area behind the slats using the empirical relationships of Fink. ${ }^{29}$ Elevator noise amplitude was estimated using the aileron noise model by Guo et al. ${ }^{30}$ while employing the directivity 
Table 2 Modifications to WingMOD for silent aircraft design.

\begin{tabular}{|c|c|}
\hline Constraint/Variable & Related Requirement \\
\hline Slat effect & Model slat removal \\
Engine mass & Model larger silent engine design \\
Engine location & Model embedded engine location, including ducting \\
Mission range & Explore effect of range upon MTOW and noise \\
Cruise Mach number & Explore effect of cruise Mach number upon MTOW and noise \\
Cruise SFC & Model performance of silent engine \\
Cruise altitude & Explore pressure variation for cruise \\
Wingspan & Examine effects of different span loadings \\
Control surface actuation & Examine controllability effects of control surface removal \\
\hline
\end{tabular}

pattern for flap noise by Chinoy. ${ }^{31}$ The undercarriage noise was estimated using the prediction method by Chinoy $^{31}$ based on the strut lengths and wheel diameters for a pair of four wheel main bogeys and a dual wheel nose unit (the geometric parameters were based on a comparison to other aircraft of similar size and weight). The noise models by Chinoy are laid out in a similar manner to $\mathrm{ANOPP}^{32}$ as they are also based on the correlations by Fink ${ }^{29}$ but include additional data to improve the empirical coefficients and directivity.

Acoustic energy was propagated from the source to the ground using the techniques of Evans. ${ }^{33}$ The propagation assumed geometric attenuation due to spherical spreading, atmospheric attenuation within a still, uniform medium, and attenuation / amplification of acoustic energy due to passage over and incidence onto a grassy surface. One-third octave sound pressure levels were created for a grid of ground locations and a fixed aircraft location. These noise levels were then converted to overall sound pressure levels of A-weighted decibels ( $\mathrm{dBA}$ ) as will be shown in the acoustics results presented in the next section.

\section{Aircraft Design Modules}

The first-principles and empirically-based aircraft design modules build on notes by Liebeck, ${ }^{34}$ which themselves draw upon Shevell ${ }^{35}$ and Schaufele. ${ }^{36}$ Those methods are applicable to conventional tubeand-wing aircraft; as will be described in the following, the SAX design tool adapts each model to be appropriate for the SAX configuration. Empirical correlations are used extensively to predict the size, shape, weight, and performance of an aircraft based upon the inputs specified by the user. A list of these inputs is shown in Table 3. This list of inputs can be specified by the user in order to produce the aircraft required or they can be varied by an optimizer in order to drive the outputs to a specific goal. The planform optimization is conducted in WingMOD which is then used as an input to the aircraft design tools. Table 3 also includes data on the engine installation. This allows the model to determine the effects of embedding the engine in the airframe, which is done by changing specific fuel consumption (SFC), engine drag, and engine weight models to take account of varying installations.

Table 3 Inputs to the SAX design tool.

\begin{tabular}{|c|}
\hline Input \\
\hline Payload Weight (pax + cargo) \\
Systems and Furnishings Weight \\
Cruise Mach Number \\
Cruise Altitude \\
Design Range \\
Planform Geometry \\
Number of Engines \\
Engine Installation Drag \\
Sea-level Static SFC \\
Takeoff Field Length \\
\hline
\end{tabular}

\section{Propulsion Module}

The propulsion module is the collection of functions that size the engine, load performance data, estimate the engine weight, and predict the engine performance at varying flight Mach numbers and altitudes. Engine sizing is done based upon takeoff performance and climb/cruise thrust requirements. The required thrust for takeoff is estimated based upon the requirement that the airframe be able to accelerate to takeoff speed, lose thrust in the most critical engine, and still be able to brake to a halt on the runway. This is known as the "Balanced Field" requirement. The required Takeoff Parameter (TOP) must be attained by a combination of the wing loading, takeoff lift coefficient, thrust loading, and the relative air density (air density divided by standard sea level air density):

$$
T O P=\frac{W / S}{\sigma C_{L_{T O}} T / W}
$$

where $T O P$ is the takeoff parameter, $W / S$ is the wing loading, $\sigma$ is the relative air density, $C_{L_{T O}}$ is the takeoff lift coefficient, and $T / W$ is the installed thrust per unit weight of the aircraft, which is the inverse of the previously defined thrust loading.

Propulsion system performance prediction is done mostly offline. GasTurb $9^{37}$ is used to produce tables of available thrust and SFC at various altitudes and flight Mach numbers based upon the assumed cycle 
parameters for the silent engine design. These tables can then be loaded into the aircraft design framework as matrices and used to look up the thrust available and the SFC at any point in the mission. Figure 2 shows a typical GasTurb output of thrust available and specific fuel consumption as functions of altitude and flight Mach number. In Figure 2, the altitude curves are the primarily vertical curves labelled with the altitude from 0 to 18,000 meters (0 to 59,054 feet). The flight Mach number curves are the primarily horizontal curves labelled with the flight Mach number from 0.0 to 0.9 .

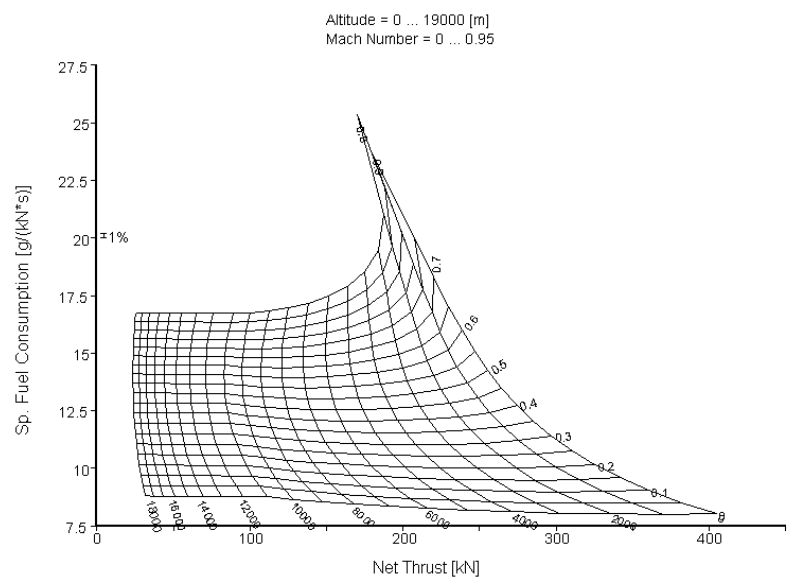

Fig. 2 Gasturb-generated data showing turbofan performance with altitude, flight Mach number.

Tables of the values in Figure 2 are created and then loaded into the propulsion module. These tables are then normalized to the sea-level static (SLS) values of thrust and SFC. In this way, when the engine size is changed in the model, the thrust available at altitude can still be predicted as a fraction of the SLS value, and the engine performance can be predicted with the same table. The SFC performance can similarly be scaled so that an engine with a better SLS value of SFC can be used, assuming the variation of SFC with altitude and flight Mach number is similar.

\section{Aerodynamic Module}

The aerodynamic module uses a combination of offline and online calculations to estimate the $C_{L}$ versus $\alpha$ curve, $C_{D}$ vs. $C_{L}$ curve, $C_{L_{\max }}$ value, and the span efficiency, where $C_{L}$ and $C_{D}$ are the lift and drag coefficients, respectively, and $\alpha$ is the angle of attack.

Lift and induced drag values are calculated offline using either AVL or WingMOD. $\mathrm{AVL}^{38}$ is an extended vortex-lattice method that includes aerodynamic analysis, trim calculations, and stability analysis. As described above, WingMOD also uses a vortexlattice aerodynamic model, which yields results consistent with those obtained using AVL. In either case, curves are fitted to produce lift as a function of angle of attack and induced drag as a function of lift.
The viscous drag calculation runs in line with the other functions in the framework. The planform is defined using a series of spanwise panels. The mission definition and a standard atmosphere calculator ${ }^{39}$ are then used to determine the flight conditions at cruise. Drag for an individual section of the wing is calculated $^{35,40,41}$ by first determining the Reynolds number per unit length $R e(c)$ as

$$
\operatorname{Re}(c)=a \cdot M_{\text {cruise }} \cdot \rho / \mu
$$

where $a$ is the speed of sound, $M_{\text {cruise }}$ is the cruise Mach number, $\rho$ is the air density, $\mu$ is the dynamic viscosity, and $c$ is the chord length. The Reynolds number is then used to calculate the empirical skin friction coefficient, $C_{f}$, as

$$
C_{f}=\frac{0.455}{\log _{10}\left(\operatorname{Re}(c) \cdot c_{\text {ave }}\right)}
$$

where $c_{\text {ave }}$ is the average chord length. A form factor $F_{f}$, which corrects for differences from flat plate results by incorporating the local wing thickness, is given by

$$
F_{f}=1+1.8(t / c)+50(t / c)^{4}
$$

where $t / c$ is the ratio of wing thickness to chord. Finally, the total skin friction drag for a section can be produced by multiplying all of these factors:

$$
D=q_{\infty}\left(C_{f} \cdot F_{f} \cdot A_{w e t}\right)
$$

where $q_{\infty}$ is the dynamic pressure and $A_{w e t}$ is the wetted area.

Once the induced and skin friction drag have been calculated, a compressibility correction is added to account for the presence of shockwaves and local streamtube constriction. This is typically on the order of $0.0004-0.001$ for an aerodynamically efficient aircraft operating at high subsonic speeds. The aerodynamic model only adds this correction during high speed flight. The total drag coefficient is therefore given by the sum of induced drag, viscous drag, and compressibility drag coefficient components.

\section{Weight Module}

The weight module provides estimates for structural, payload, systems, propulsion and fuel weights. The payload and systems weights are inputs, the values for which are based upon passenger number, configuration, engine size and number, landing gear weight, etc. They are set based upon estimates made before the design iteration is started. The propulsion weight is based upon the size of the engine and the type of installation (podded nacelle, BLI inlet, etc.). Once the static sea-level thrust is set for an iteration, the weight of the engine can be computed from that thrust value and an estimate of the thrust to weight ratio for the engine type. The fuel weight is calculated 
based upon a mission simulation run during each iteration.

The structural weight calculation is based on empirical formulae, which yields a serious challenge. A great deal of empirical data exist for the calculation of weights of wings, tails, landing gear, and every other component on a conventional commercial aircraft. However, the silent aircraft's structure has many differences from that of conventional commercial aircraft. The flying wing design incorporates a non-cylindrical pressurized cabin into the center wing, highly tapered outer wings, and large winglets with control surfaces at the wingtips. These structures will not be modeled well by existing empirical fuselage and wing weight estimations. For this reason, several WingMOD designs are used to produce a least-squares quadratic response surface model (RSM). This surface is then used to predict the structural weight of the silent aircraft. The RSM model takes the form

$$
W_{\text {struct }}=\beta_{0} \cdot y_{0}+\beta_{1} \cdot y_{1}+\beta_{2} \cdot y_{2} \ldots
$$

where $W_{\text {struct }}$ is the structural weight estimate produced by the model, the $\beta_{i}$ are constant coefficients, and $y_{i}$ are attributes of the airframe that are known. The coefficients in (6) are determined using a least-squares fit to WingMOD data, as described in Diedrich. $^{42}$

\section{Climb Module}

The climb module estimates the climb rate of the aircraft based upon the thrust available, drag produced, and weight of the aircraft at an average point in the climb which will be defined shortly. This climb rate is extrapolated to determine the fuel, time, and distance required to reach cruising altitude.

The first step in the climb performance prediction is to set the values of altitude and speed which will be used to model performance. In this case, a fraction of $20 / 35$ of the cruise altitude is used as the climb altitude. This is a fraction used by Liebeck ${ }^{34}$ as being indicative of average climb performance. The climb velocity is set to the limit for operations in U.S. Class $\mathrm{B}$ airspace (250 knots). This limit is set because a fair amount of maneuvering is likely to be done in addition to climbing as the aircraft attempts to reach cruise altitude. Therefore, despite the fact that the aircraft will accelerate to speeds greater than 250 knots, it is likely to be a good indicator of the speed achievable during a significant portion of the time the aircraft spends climbing to cruising altitude.

Once the speed and altitude are fixed, the thrust required for straight and level flight at these conditions is calculated as

$$
T_{c l}^{r}=q_{c l} f_{\text {sum }}+\frac{g \cdot m_{c l}}{q_{c l} \pi b^{2} e}
$$

where the subscript $c$ represents the climb condition. $T^{r}$ is the thrust requirement, $f_{\text {sum }}$ is the flat plate equivalent drag on the airframe, $g$ is the gravitational constant, $m$ is the mass of the aircraft, $b$ is the span, and $e$ is the Oswald efficiency factor.

The thrust requirement from (7) is checked against the propulsion module's thrust available estimate at this altitude and flight Mach number. Once the amount of thrust available is known, the rate of climb can be computed. This is done by assuming that all excess specific energy available to the aircraft is converted into potential energy in the form of altitude, yielding

$$
R O C=V_{c l} \frac{T_{c l}^{a}-T_{c l}^{r}}{g \cdot m_{c l}}
$$

where $R O C$ is the rate of climb, $V$ is the velocity of the aircraft, and $T^{a}$ is the available thrust estimate from the propulsion module.

Once the rate of climb is calculated, the time, range, and fuel used for the climb can easily be calculated using the following relations:

$$
\begin{gathered}
t_{c l}=\frac{h_{c r}}{R O C} \\
R_{c l}=V_{c l} \cdot t_{c l} \\
F_{c l}=t_{c l} \cdot T_{c l}^{a} \cdot S F C_{c l}
\end{gathered}
$$

where $t_{c l}$ is the time required to climb, $h_{c r}$ is the cruise altitude, $R_{c l}$ is the distance travelled during climb, $F_{c l}$ is the fuel burned during climb, and $S F C$ is the thrust specific fuel consumption calculated by the propulsion module.

\section{Cruise Module}

Once the climb module has produced values for the fuel burned and range covered during climb, the cruise module is used to estimate cruise performance with the Breguet range equation

$$
R=\frac{L}{D} \frac{V}{S F C} \ln \left(\frac{W_{0}}{W_{1}}\right)
$$

Solving for the unknown final cruise weight yields

$$
W_{1}=W_{0} e^{\frac{-S F C \cdot R}{L / D \cdot V}}
$$

In Equations (12) and (13), $R$ is the distance remaining to travel after the climb distance has been subtracted from the nominal range, $L / D$ is the cruise lift to drag ratio, $V$ is the cruise velocity, and $W_{0}$ and $W_{1}$ are the cruise beginning and cruise ending weights of the aircraft, respectively.

The cruise SFC is estimated by the propulsion module. The cruise velocity is taken from the atmospheric conditions and the cruise Mach number. The cruise $\mathrm{L} / \mathrm{D}$ value is computed by the aerodynamic module using an estimated average cruise weight. Once all of these factors are computed, the final cruise weight, $W_{1}$, can be computed using (13). The estimated cruise 
fuel burn is then computed as the difference between initial and final cruise weight $\left(W_{0}-W_{1}\right)$.

The cruise module outputs the estimated cruise fuel burn, the thrust available during cruise, and the thrust required during cruise. These values are checked in the mission loop to determine if the aircraft can perform the design mission.

\section{The Silent Aircraft Design}

Design results and acoustic assessment are presented for an aircraft that is designated SAX12. This aircraft is designed to carry 215 passengers in a multiple class, international configuration a distance of 5,000 nautical miles with the lightest possible design while integrating constraints that represent low noise technologies. The choice here to minimize the MTOW is due to an assumption that an aircraft of a given configuration and technology level will become quieter with weight reduction. The planform of the aircraft is shown in Figure 3. The silent aircraft design utilizes the engine design of Hall and Crichton, ${ }^{21,22}$ which uses a BLI embedded engine installation and has a specific fuel consumption (SFC) of $0.50 \mathrm{lbm} / \mathrm{lbf}-\mathrm{hr}$.

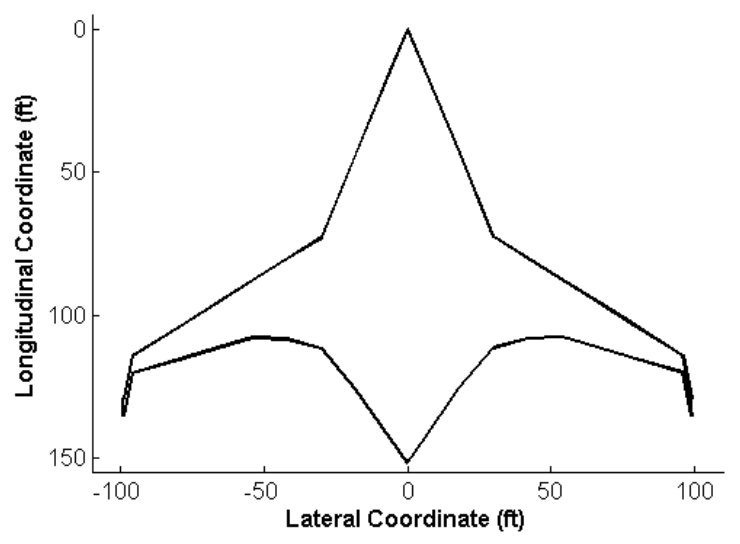

Fig. 3 The silent aircraft planform.

The choice of a BLI engine installation dictates to a certain extent the number and location of the engines. Figure 4 shows a possible configuration with four engines mounted on the rear portion of the upper wing surface using BLI inlets. The choice of four small engines as opposed to two large turbofans allows for greater embedding of the engines within the airframe. A detailed study on the choice of the propulsion system and installation issues can be found in Hall and Crichton. ${ }^{21}$ The mounting of the engines near the trailing edge is a byproduct of the SAX design. The engines effectively balance the airframe by offsetting the weight of the payload and associated furnishings and systems. The mounting location also affords excellent BLI potential, as the boundary layer is fully developed at the rear of the wing, so ingestion has the greatest effect. The long exhaust ducts allow for liners to reduce rearward propagating fan and turbine noise.

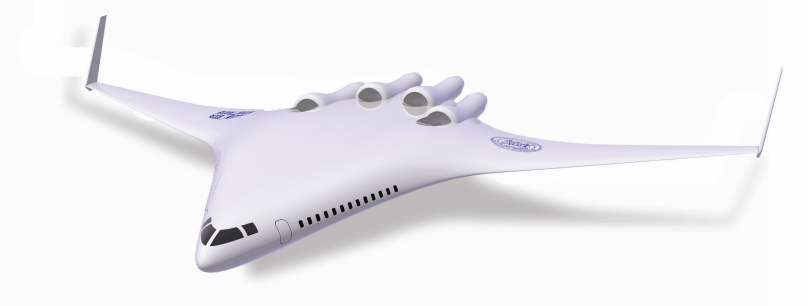

Fig. 4 A 3-D rendering of the silent aircraft ${ }^{43}$ [cited Jan. 2005].

Table 4 SAX12 key performance figures.

\begin{tabular}{|c|c|}
\hline Parameter & Value \\
\hline Planform Area $\left(\mathrm{ft}^{2}\right)$ & 8,114 \\
Wingspan (ft) & 192 \\
MTOW (lb) & 340,151 \\
Begin Cruise L/D & 21.9 \\
Cruise Mach number & 0.80 \\
Initial cruise altitude (ft) & 40,000 \\
Thrust loading (lb/lbf) & 2.66 \\
Wing loading (lb/ft $\left.{ }^{2}\right)$ & 41.9 \\
Fuel Burn (gal/nm/pax) & 0.0114 \\
\hline
\end{tabular}

Table 4 lists performance figures for SAX12 and reveals several key results that stem from the low noise requirements placed upon the SAX configuration. The thrust loading for SAX12 is quite low, meaning that the installed thrust is high. Table 1 lists an 800passenger BWB as having a lower installed thrust per pound of aircraft than any other aircraft in the table; however, as a result of the low noise requirements of SAX12, the installed thrust is very high. This stems partially from the choice of a UHBR turbofan. Such a powerplant will achieve low jet velocity at takeoff, producing good acoustic performance, but will suffer from very large thrust lapse. The engines are sized by the required thrust at top of climb, not by the required takeoff thrust.

The silent aircraft design range was determined based on the results of a trade study performed with WingMOD. SAX aircraft designs were created for ranges from $4000 \mathrm{~nm}$ to $8000 \mathrm{~nm}$. In each case, the aircraft was designed to minimize MTOW. The fuel burn estimates, defined as design fuel minus reserves per design range and passenger capacity, of the resulting aircraft are plotted in Figure 5. Also plotted in Figure 5 are the data for part of the existing fleet. ${ }^{4-46}$ The vertical lines of the data from Lee et al. show the variation in fuel burn reported by the airlines. The fuel burn estimate for the Boeing 787-3 aircraft was based upon the payload-range diagrams within Boeing's latest airport planning guide, which show the 
787-3 burns $83 \%$ of the fuel of a Boeing 767-300 for the same payload and range. ${ }^{47}$ The silent aircraft design labelled SAX10 corresponds to a range of 4000nm and an earlier engine design with SFC of $0.54 \mathrm{lbm} / \mathrm{lbf}-$ hr. A detailed performance assessment of the SAX10 design is given in Diedrich. ${ }^{42}$ All other SAX designs in Figure 5 use an engine with SFC of $0.50 \mathrm{lbm} / \mathrm{lbf}-\mathrm{hr}$.

The absolute noise level associated with the goal to reduce noise below the background noise outside the airport boundary is more easily achieved for smaller sized aircraft. This suggests that the design range specification should be set as low as possible. However, Figure 5 shows that, for the silent aircraft configuration, an increase in range from 4000nm to 5000nm can be achieved with very little increase in fuel burn. This is due to the fact that excess fuel volume is available for the 4000nm design, so that additional range can be achieved with very little increase in operating empty weight $(\mathrm{OEW})$. Figure 6 shows further that the low fuel burn of the SAX designs is achieved by a high $M L / D$ (Mach number times lift-to-drag ratio) and the relatively low SFC of the engine, both of which counteract the relatively high empty weight fraction (OEW/MTOW). For comparison, the $M L / D$, SFC, and empty weight fractions for a Boeing 777 are 15.5, 0.55 and 0.49 , respectively. ${ }^{46}$ The SAX12 fuel burn estimate assumes no impact on thrust due to BLI; this should yield a conservative estimate.

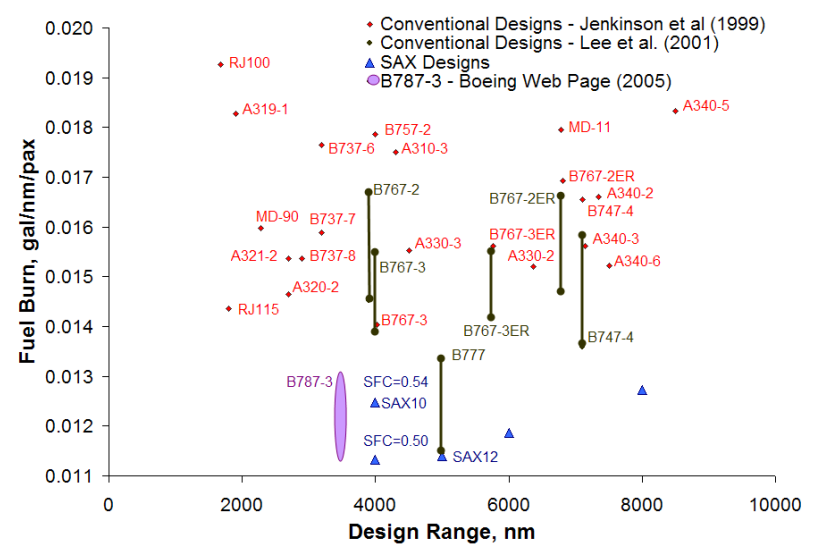

Fig. 5 Comparison of the existing fleet fuel burn $^{44-46}$ and projected 787-3 fuel burn ${ }^{47}$ to potential silent aircraft planforms of varied range and engine SFC.

The acoustic data in Figures 7, 8 and 9 show a noise assessment of SAX12. The noise contours on the ground are plotted for the sideline position (measured on takeoff), the takeoff flyover position (when the aircraft is about to cut back throttle position), and the approach position (when the aircraft passes over the airport boundary on approach to landing). For each position, a breakdown of the individual noise components is also plotted along the trajectory. For comparison, the FAA reports sound levels of 76.4 and

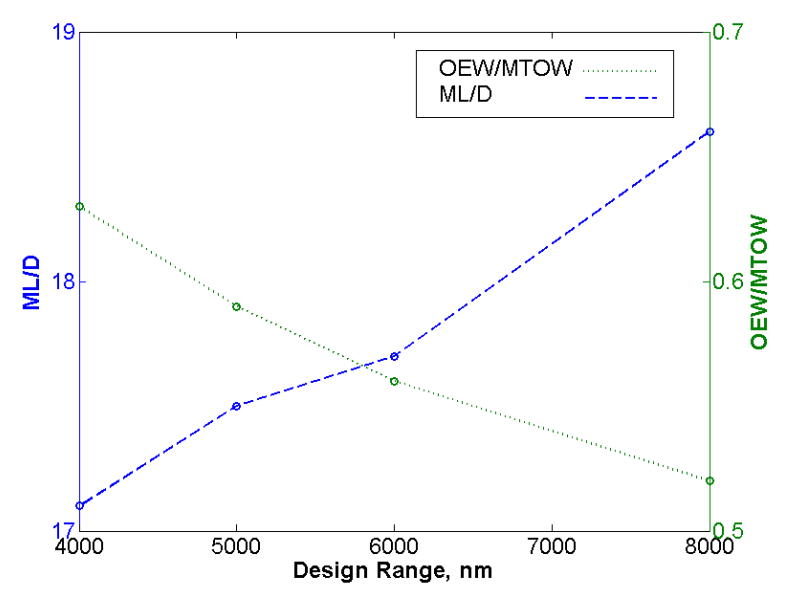

Fig. 6 Impact of design range on empty weight fraction (OEW/MTOW) and cruise performance $(M L / D)$.

89.3 dBA, respectively, for a Boeing 767-300 at takeoff and approach certification points. ${ }^{48}$ This is a good choice of aircraft for comparison given its similar size to SAX12.

Figures 7, 8 and 9 show that, while many of the noise components exhibit large reductions in comparison with current transports of the size of SAX12, the overall noise contours on the ground do not achieve the stated goal of an aircraft inaudible outside the airport perimeter. The component noise breakdowns show that significant aircraft noise reduction can only be achieved if all sources of noise are reduced dramatically. As such, the data highlight the remaining barriers that must be addressed to achieve a silent aircraft. These barriers will be overcome through configuration choices and the incorporation of low-noise engine and airframe technologies, as discussed in more detail below.

For the engine noise, the jet (engine exhaust) noise is very low for both takeoff flyover and approach positions. On takeoff, this low jet noise is achieved through the innovative silent engine design, which employs a variable exhaust nozzle. ${ }^{21,22}$ The noise from the fan exceeds the required levels, and is currently being addressed through an engine redesign. ${ }^{23}$

Figures 8 and 9 show high airframe noise levels for the SAX12 design. SAX12 utilized a conventional approach trajectory of $75 \mathrm{~m} / \mathrm{s}$ with a 3 degree glide slope with conventional slats, large elevators and a traditional undercarriage (four-wheel main bogeys). Significant noise reduction should be possible through the use of a slow and steep glide slope, a faired undercarriage, unconventional leading edge devices for high lift, and thrust vectoring for pitch trim (instead of elevators). Research to incorporate these technologies to the silent aircraft design is ongoing. Further details on airframe noise reduction for the silent aircraft can 

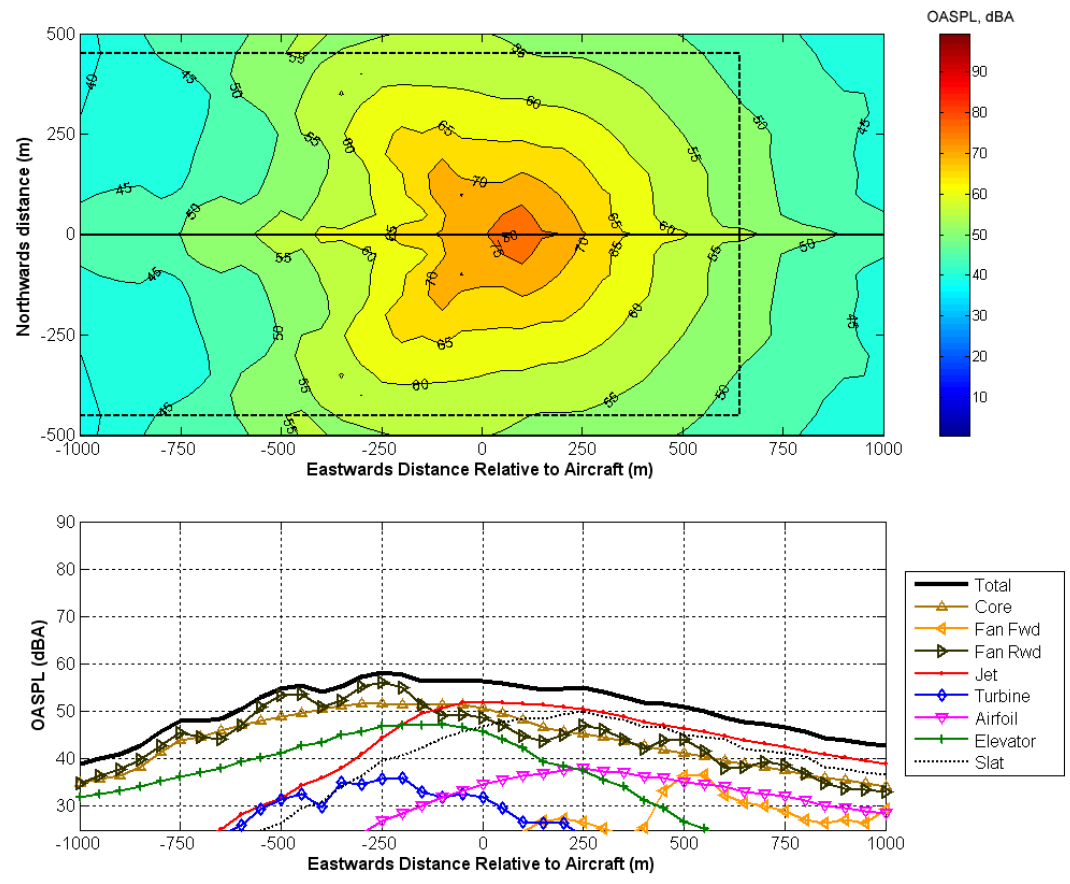

Fig. 7 SAX12 sideline noise estimate (OASPL, dBA) near the airport perimeter (dotted lines) with the individual noise components broken out along the trajectory.
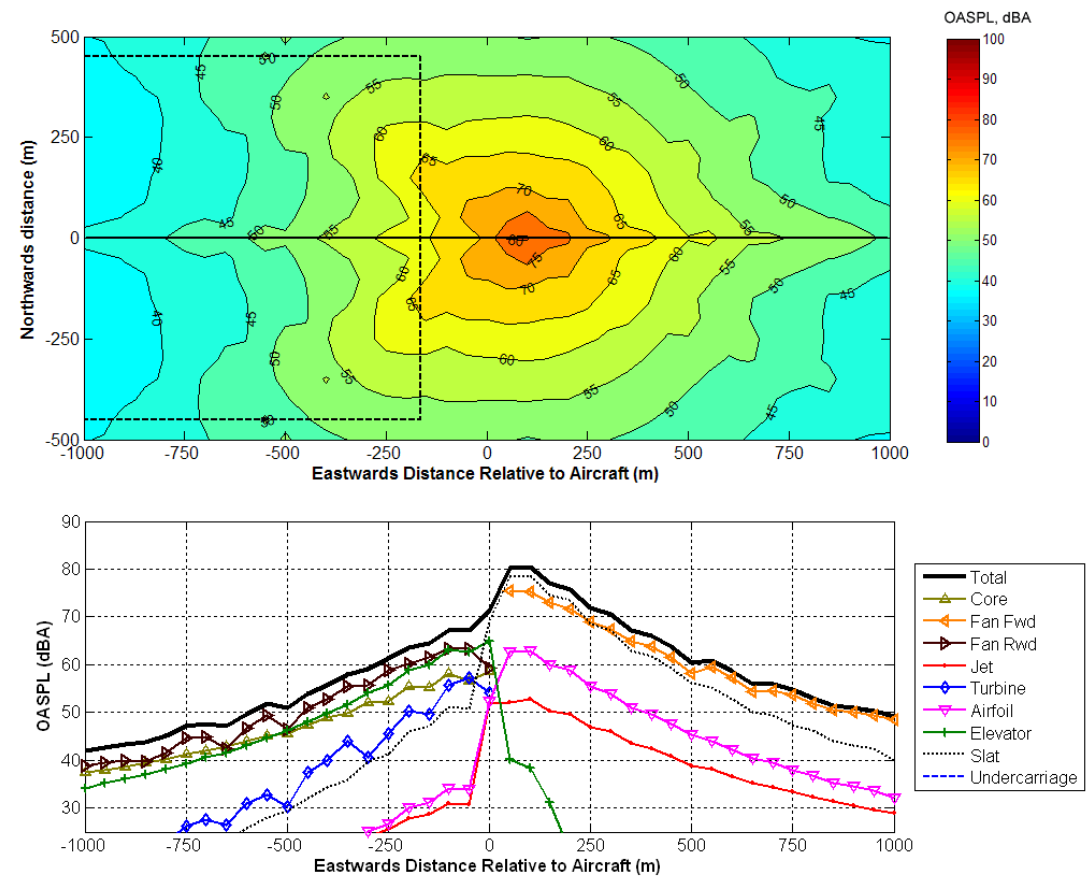

Fig. 8 SAX12 takeoff flyover noise estimate (OASPL, dBA) as the aircraft passes over the airport perimeter (dotted lines) with the individual noise components broken out along the trajectory. 

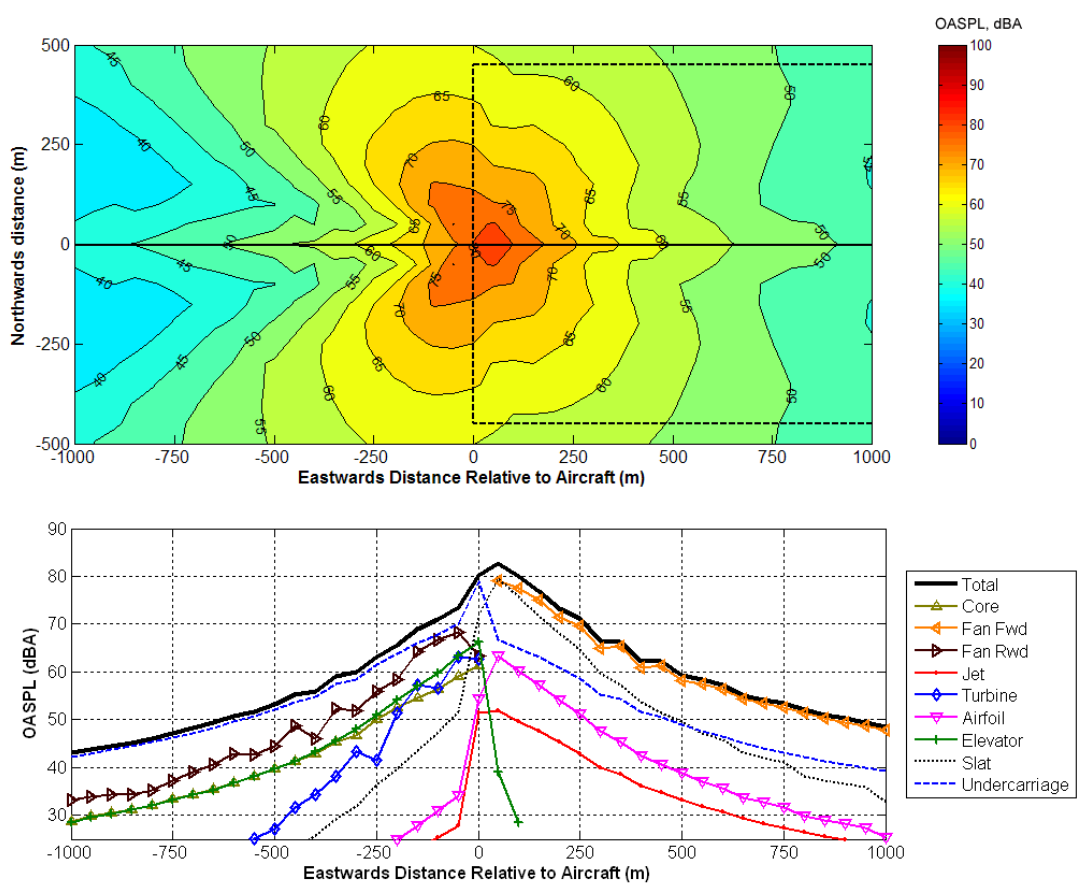

Fig. 9 SAX12 approach noise estimate (OASPL, dBA) as the aircraft passes over the airport perimeter (dotted lines) with the individual noise components broken out along the trajectory.

be found in Hileman et al. ${ }^{16}$

\section{Conclusions}

A multidisciplinary design framework has been described that enables design of a novel aircraft configuration with a step change in noise reduction. Through careful selection of aircraft configuration and mission parameters, a design is achieved that has significantly reduced noise compared with current commercial aircraft of similar size, but fuel burn competitive with next-generation aircraft, such as the 787 . While the current design does not achieve the stated goal of being inaudible outside the airport perimeter, acoustic assessments demonstrate the further technology developments that are necessary. In particular, research is ongoing to reduce engine fan noise through an engine redesign, and to reduce airframe noise through a combination of operational procedures and quiet airframe technologies.

\section{Acknowledgments}

The authors acknowledge the contributions of the Silent Aircraft Initiative researchers at Cambridge University and MIT, and funding from the CambridgeMIT Institute. We also gratefully acknowledge collaborations with the Blended-Wing-Body design team, and in particular, the technical guidance of R. Liebeck, S. Wakayama, and R. Gilmore of Boeing Phantom Works.

\section{References}

${ }^{1}$ Kroo, I., "MDO applications in preliminary design: status and directions," AIAA Paper 97-1408, presented at 38th AIAA Structures, Structural Dynamics, and Materials Conference, Kissimmee, FL, April 7-10, 1997.

${ }^{2}$ Sobieszczanski-Sobieski, J., Bartelemy, J.-F., and Giles, G., "Aerospace engineering design by systematic decomposition and multilevel optimization," Proceedings of 14th Congress of the International Council of the Aeronautical Sciences, Toulouse, France, 1984.

${ }^{3}$ Sobieszczanski-Sobieski, J. and Haftka, R., "Multidisciplinary aerospace design optimization: survey of recent developments," Structural Optimization, Vol. 14, No. 1, 1997, pp. 1-23.

${ }^{4}$ Wakayama, S., "Blended-Wing-Body Optimization Problem Setup," AIAA Paper 2000-4740, 2000.

${ }^{5}$ Venter, G., and Sobieszczanski-Sobieksi, J., 2002, "Multidisciplinary Optimization of a Transport Aircraft Wing using Particle Swarm Optimization," AIAA Paper 2002-5644.

${ }^{6}$ Liebeck, R. H., Page, M. A., and Rawdon, B. K., 1998, "Blended-Wing-Body Subsonic Commercial Transport," AIAA Paper 1998-0438.

${ }^{7}$ Liebeck, R. H., "Design of the Blended Wing Body Subsonic Transport," Journal of Aircraft, vol. 41, no. 1, pp. 10-25, Jan. 2004.

${ }^{8}$ Antoine, N. and Kroo, I., "Aircraft Optimization for Minimal Environmental Impact," Journal of Aircraft, Vol. 41, No. 4, 2004 .

${ }^{9}$ Antoine, N., Aircraft design for minimal environmental impact, Ph.D. thesis, Stanford University, June 2004.

${ }^{10}$ Antoine, N. E., Kroo, I. M., Willcox, K., and Barter, G., 2004, "A Framework for Aircraft Conceptual Design and Environmental Performance Studies," AIAA Paper 2004-4314.

${ }^{11}$ Waitz, I. A., Lukachko, S. P., and Lee, J. J., 2003, "Military Aviation and the Environment: Historical Trends and Comparison to Civil Aviation," AIAA Paper 2003-2620.

${ }^{12}$ Pilczer, D., Noise Reduction Assessments and Preliminary Implications for a Functionally Silent Aircraft, S.M. Thesis, 
Massachusetts Institute of Technology, Cambridge, MA, June 2003

${ }^{13}$ Manneville, A., Pilczer, D., and Spakovszky, Z., "Noise Reduction Assessments and Preliminary Design Implications for a Functionally-Silent Aircraft," AIAA Paper 2004-2925, 10th AIAA/CEAS Aeroacoustics Conference, Manchester, United Kingdom, May 10-12, 2004.

${ }^{14}$ Lilley, G. M., May 2004, "A Quest for Quiet Commercial Passenger Aircraft for Take-off and Landing," AIAA Paper 2004-2922.

15 Jane's Information Group Ltd, Jackson, P. (Editor), 2004, "Jane's All the World's Aircraft 2004-2005," Thanet Press Ltd.

${ }^{16}$ Hileman, J.I., Spakovszky, Z.S., Drela, M. and Sargeant, M., "Aerodynamic and Aeroacoustic 3D Design for Silent Aircraft," AIAA paper 2006-0241, 44th AIAA ASM Conference, Reno, Nevada, 2006.

${ }^{17}$ Heidmann, M.F. , 1975, "Interim Prediction Method for Fan and Compressor Source Noise," NASA Report TM X-71763.

${ }^{18}$ Stone, J.R. , 1974, "Interim Prediction Method for Jet Noise," NASA Report TM X-81470.

${ }^{19}$ Matta, R.K., Sandusky, G.T., Doyle, V.L. , Feb 1977, "GE Core Engine Noise Investigation - Low Emission Engines," $F A A-R D-77-4$

${ }^{20}$ Emmerling, J.J, Kozin, S.B., Matta, R.K. , Mar 1976, "Core Engine Noise Control Program. Volume III, Supplement I - Prediction Methods," FAA-RD-74-125, III-I.

${ }^{21}$ Hall, C.A. and Crichton, D., "Engine and Installation Configurations for a Silent Aircraft," ISABE-2005-1164, Proceedings of International Symposium on Air Breathing Engines, Munich, Germany, 2005.

${ }^{22}$ Hall, C.A. and Crichton, D., "Engine Design studies for a Silent Aircraft," GT2006-90559, to appear in Proceedings of ASME Turbo Expo, Barcelona, Spain, May 2006.

${ }^{23}$ Crichton, D., Xu, L., and Hall, C.A., "Preliminary Fan Design for a Silent Aircraft," GT2006-90564, to appear in Proceedings of ASME Turbo Expo, Barcelona, Spain, May 2006.

${ }^{24}$ Agarwal, A. and Dowling, A. P., "Low Freqency Acoustic Shielding of Engine Noise by the Silent Aircraft Airframe," AIAA 2005-2996, 11th AIAA/CEAS Aeroacoustics Conference, Monterey, California, 2005.

${ }^{25}$ Law, T., "Personal communication," January 2005.

${ }^{26}$ Ffowcs Williams, J. and Hall, L., "Aerodynamic Sound Generation by Turbulent Flow in the Vicinity of a Scattering Half Plane," Journal of Fluid Mechanics, Vol. 40, 1970, pp. 65770 .

${ }^{27}$ Brooks, T.F., Pope, D.S., Marcolini, M.A., Jul 1989, "Airfoil Self-Noise and Prediction," NASA-RP-1218.

${ }^{28}$ Lockard, D. and Lilley, G., "The Airframe Noise Reduction Challenge," NASA TM-2004-213013, 2004.

${ }^{29}$ Fink, M.R., Mar. 1977, "Airframe Noise Prediction Method," FAA-RD-77-29.

${ }^{30}$ Guo, Y., Yamamoto, K., and Stoker, R., "ComponentBased Empirical Model for High-Lift System Noise Prediction," Journal of Aircraft, Vol. 40, No. 5, 2003, pp. 914-922.

${ }^{31}$ Chinoy, C., "Airframe Noise Prediction," Engineering Sciences Data Unit (ESDU) Airframe Noise Prediction Manual, Item No. 90023 Amendment C, ESDU International plc, London, UK, June 2003.

${ }^{32}$ Zorumski W.E. , Feb. 1982, "Aircraft Noise Prediction Program Theoretical Manual," NASA Report TM-83199, Part 2.

${ }^{33}$ Evans, P., "An Introduction to Aircraft Noise Lateral Attenuation," Engineering Sciences Data Unit (ESDU) Lateral Attenuation Manual, Item 81035, ESDU International plc, London, UK, November 1981.

${ }^{34}$ Liebeck, R. H., Sep. 2002, Lecture Notes from MIT Class, 16.885J: Aircraft Systems Engineering.

${ }^{35}$ Shevell, R. S., 1989, "Fundamentals of Flight, Second Edition,", Prentice Hall, Inc.
${ }^{36}$ Schaufele, R. D., "The Elements of Aircraft Preliminary Design", Aries Publications, 2000.

${ }^{37}$ Kurzke, J., 2001, "A Program to Calculate Design and Off-Design Performance of Gas Turbines," GasTurb 9 User's Manual.

${ }^{38}$ Drela, M., http://web.mit.edu/drela/Public/web/avl/.

${ }^{39}$ Kroo, I. M., Standard Atmosphere Computations, Apr. 1997, [Cited Jan 2004], http://aero.stanford.edu/stdatm.html.

${ }^{40}$ Hoerner, S. F., 1981, "Fluid Dynamic Drag: Practical Information on Aerodynamic Drag and Hydrodynamic Resistance," Hoerner Fluid Dynamics.

${ }^{41}$ von Karman, T., 1934, "Turbulence and Skin Friction", Journal of the Aeronautical Sciences, vol 1, no 1.

${ }^{42}$ Diedrich, A., The multidisciplinary design and optimization of an unconventional, extremely quiet aircraft, Master's thesis, MIT, February 2005.

${ }^{43}$ The Silent Aircraft Initiative, [Cited Jan. 2005], "Silent Aircraft Initiative ... a new approach," http://silentaircraft.org.

${ }^{44}$ Jenkinson, L.R., Simpkin, P. and Rhodes, D., Civil Aircraft Design, AIAA Education Series, Reston VA, 1999.

${ }^{45}$ Jenkinson, L.R., Simpkin, P. and Rhodes, D., "Web Database for Civil Jet Aircraft Design," http://www.bh.com/companions/034074152X/appendices/dataa/default.htm, Butterworth-Heinemann, UK, 1999.

${ }^{46}$ Lee, J.J., Lukachko, S.P., Waitz, I.A. and Schafer, A., "Historical and Future Trends in Aircraft Performance, Cost and Emissions," Annu. Rev. Energy Environ, Vol. 26, pp. 167200, 2001.

${ }^{47}$ The Boeing Company, "The Boeing 787 Dreamliner Airport Compatibility,"

http://boeing.com/assocproducts/aircompat/plan_manuals.html, Sept. 2005.

${ }^{48}$ Federal Aviation Authority, AC36-3H, "Estimated Airplane Noise Levels in A-weighted Decibels," http://www.faa.gov/about/office_org/headquarters_offices/aep/noise_levels, Apr. 2001. 